Short report

\title{
Idiopathic dystonia and cervical spondylotic myelopathy
}

\author{
J A WATERSTON, * M SWASH, * ES WATKINS $\dagger$ \\ From the Departments of Neurology, ${ }^{*}$ and Neurosurgery, $\dagger$ The London Hospital, Whitechapel, London
}

SUMMARY Cervical myelopathy developed in two patients with idiopathic torsion dystonia. There were marked spondylotic changes in both patients, probably attributable to the incessant dystonic movements of the neck. Previous cervical spine surgery may have exacerbated the myelopathy in one of the patients. Cervical myelopathy complicating idiopathic dystonia must be distinguished from $\vec{\omega}$ other causes of neurological deterioration, since it may be improved by appropriate neurosurgical treatment.

The clinical spectrum of dystonia encompasses a wide variety of movement disorders ranging from writer's cramp to generalised dystonia. ' Idiopathic dystonia is characterised by the absence of clinical involvement of other parts of the nervous system, such as the cerebellum, pyramidal system, retina and cerebral cortex. When there are signs of dysfunction in any of these systems, symptomatic dystonia, which is secondary to some underlying condition, should be suspected. Exceptions to this clinical axiom occur. For example, the other clinical features may complicate corrective neurosurgical procedures or result from unrelated neurological disease. ${ }^{2}$ We report a further exception to this axiom; the development of cervical spondylotic myelopathy (CSM) caused or exacerbated by dystonia.

\section{Case reports}

Case 1 A 61 year old man with spasmodic torticollis initially presented with involuntary head and neck movement consisting of irregular jerking with torticollis, retrocollis, and facial grimacing. There was clinical evidence of cervical spondylosis, with weakness of left triceps and finger extensors, absence of the triceps jerk and C7 sensory loss but cervical myelography showed no evidence of cord compression. No primary cause for the dystonia was found, and treatment with tetrabenazine and haloperidol was unsuccessful. Because of increasing disability, he was admitted for

Correspondence to: Dr M Swash, Department of Neurology, The London Hospital, Whitechapel, London E1 1 BB, United Kingdom.

Received 17 November 1988 and in revised form 24 May 1989. Accepted 27 June 1989 a trial of high cervical dorsal column stimulation. An $\vec{N}$ extradural stimulator was placed at the $\mathrm{Cl}$ level without laminectomy, but this failed to alleviate his symptoms.

His disability remained unchanged for several years bo three months before his last admission, aged 67 years, ho complained of increasing pain in his left shoulder, weaknes in both arms and legs, and urinary hesitancy. During the period he became unable to stand or walk. On examination the torticollis was unchanged, with jerking of the head to the right and some involuntary movement in the right arm. There. was wasting of the intrinsic muscles of both hands are triceps; all the tendon reflexes in the left arm and the right $\vec{\omega}$ triceps jerk were absent. There was a spastic paraplegia with bilateral extensor plantar responses and a sensory level was present at $\mathrm{T} 1$.

Cervical spine radiographs showed marked degenerative changes, particularly at the $\mathrm{C} 5, \mathrm{C} 6$ and $\mathrm{C} 7$ levels, and myelography revealed a sub-total, extradural block to the flow of contrast at $\mathrm{C} 7 / \mathrm{T} 1$ with a narrow canal at $\mathrm{C} 5 / 6$ and C6/7 (fig 1). A decompressive laminectomy was performed at these levels, but he did not improve. His dystonia became more marked and, after a stormy post operative course, he developed respiratory failure and died.

Case 2 This 19 year old student developed dystonia at the age of 14 years. Following the administration of prochlorperazine after a routine appendicectomy he experienced a short episode of torticollis and nine months later, developed fixed laterocollis to the left. The dystonia gradually worsened and he developed generalised torsion dystonia with fixed flexion deformities of the left arm and leg. Investigation failed to reveal an underlying cause.

During the next two years he continued to deteriorate despite medical treatment and a posterior cervical rhizotomy, becoming bed-ridden and affected by attacks of severe tremor. A right thalamotomy abolished the tremor and fixed dystonic posture of his left limbs but failed to influence the fixed laterocollis. After insertion of a dorsal column 

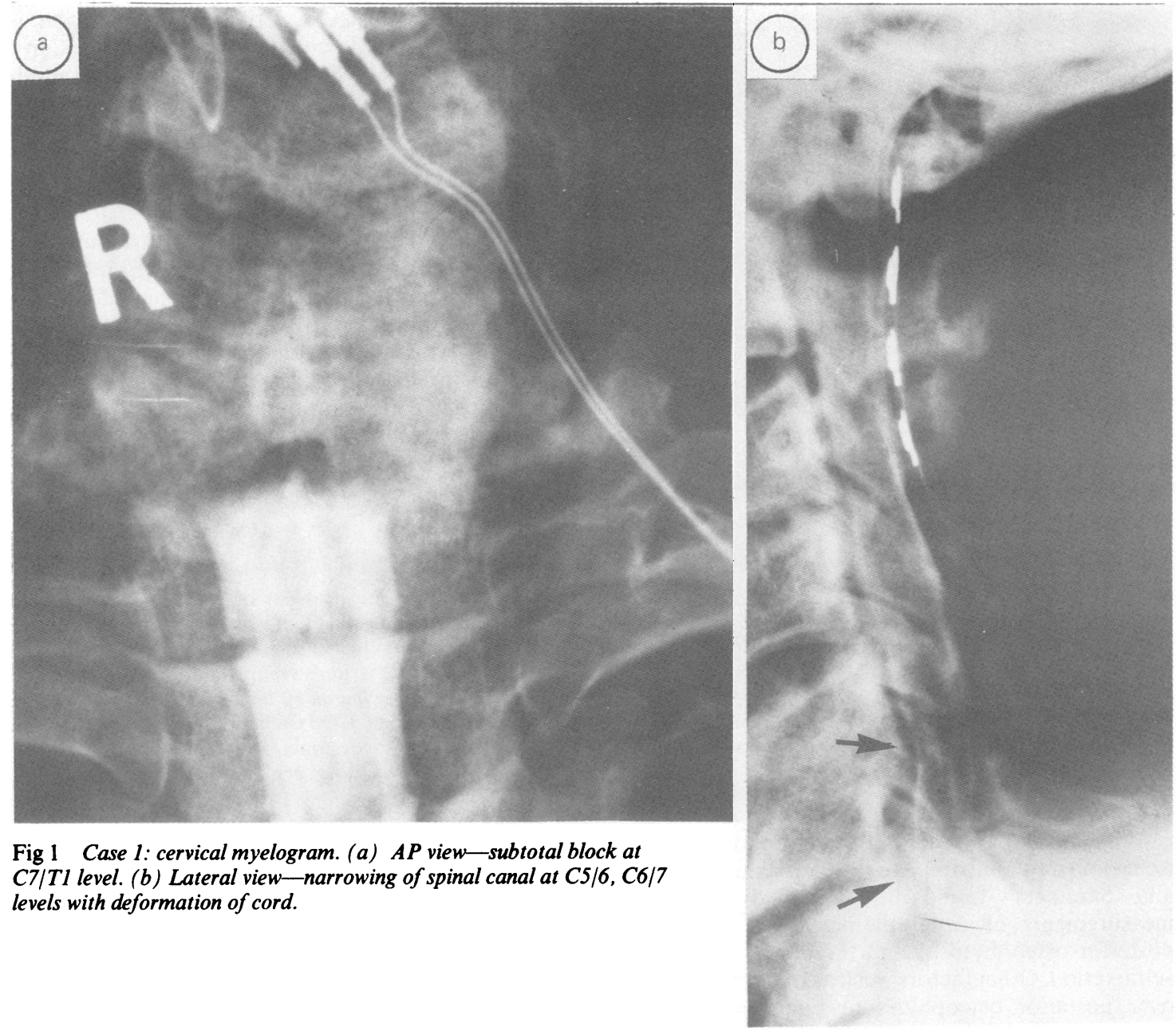

Fig 1 Case 1: cervical myelogram. (a) AP view-subtotal block at $C 7 / T 1$ level. (b) Lateral view-narrowing of spinal canal at C5/6, C6/7 levels with deformation of cord.

stimulator at the cervico-medullary junction there was marked improvement in his neck posture and mobility, and he was able to return to college and to play sport.

One year later he was readmitted with increasing generalised dystonia. A new power source for the dorsal column stimulator was implanted, but he continued to deteriorate. A left thalamotomy was then performed with some improvement in the dystonia affecting his right hand. He initially maintained this improvement but then over several weeks noticed increasing limb dystonia with frequent dystonic spasms. Several explorations of the stimulator site and its connections were undertaken for recurrent technical difficulties. On the day following one such procedure he developed rapidly progressive weakness in both arms, paraesthesiae below the neck and then the abrupt onset of an almost complete flaccid quadriparesis with respiratory difficulties and a sensory level in the mid-cervical region. A myelogram showed severe cervical spondylosis with marked kyphosis and forward subluxation of $\mathrm{C} 2$ on $\mathrm{C} 3$, and $\mathrm{C} 3$ on $\mathrm{C4}$, and narrowing of the cervical canal at $\mathrm{C} 3$ and $\mathrm{C} 4$, the level of the stimulating electrode. There was angulation of the cord at the level of the $\mathrm{C} 3 / \mathrm{C} 4$ subluxation (fig 2).

Immediate exploration of the stimulator site was perfor- med but little improvement occurred. A posterior cervical fusion was then performed from the occiput to $\mathrm{C} 4$, with synchronous anterior fusion at the $\mathrm{C} 3 / \mathrm{C} 4$ level. Over the course of several months there was gradual improvement, particularly in the left arm and leg.

\section{Discussion}

It is prudent to recognise CSM as a cause of functional deterioration in the dystonic patient. In case 1 , cervical spondylosis without myelopathy was present at the time of diagnosis of the dystonia. The patient developed a cervical cord syndrome due to extradural compression from osteophytes at the lower cervical levels. In case 2 , severe cervical spondylosis with subluxation and kyphosis caused an acute myelopathy, probably due to cord traction across the kyphotic zone. In this case, although the cervical spine deformity was probably exacerbated by previous cervical laminectomy, it seems likely that the spondylotic changes were due to the dystonia. 


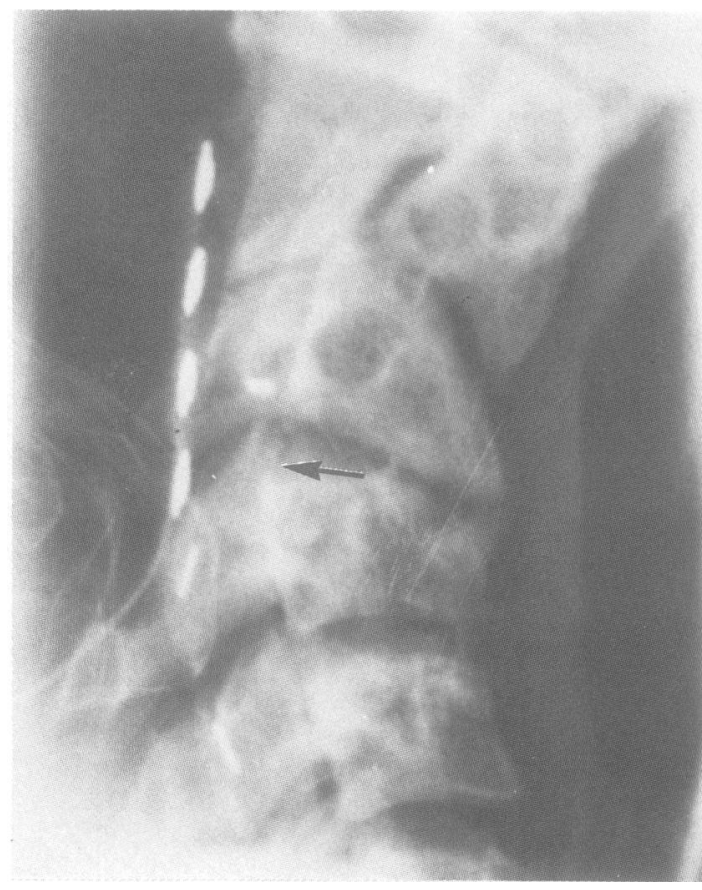

Fig 2 Case 2: cervical myelogram, lateral viewsubluxation of $C 2$ on $C 3, C 3$ on $C 4$ with angulation and narrowing at $C 3 / 4$ level.

Compression is thought to be the main factor causing myelopathy in cervical spondylosis, ${ }^{3}$ but ischaemia may contribute to the cord damage. ${ }^{4}$ Barnes and Saunders ${ }^{5}$ found little predictive value in measurements of canal diameter, the amount of posterior osteophytosis, and the degree of vertebral subluxation. Other factors, such as traction of the cord over posterior osteophytes or compromise of the transverse area of the cervical canal area during some movements may be important, and post-operative reduction in cervical mobility correlates well with clinical improvement. ${ }^{5}$ Considerable movement and stretching of the cord occurs during normal neck flexion and quite large localised forces are produced by osteophytic bars projecting into the cervical canal during such manoeuvres. ${ }^{6}$ The cord may be rendered ischaemic during such movements, when the crosssectional area of the canal decreases in extension by up to $16 \% .^{7}$ The normal canal lengthens in flexion and shortens in extension, but if cord movement is restricted by root sleeve and dural fibrosis or osteophytic bars, then traction forces may develop. Adams and Logue $^{8}$ considered that cord traction was a significant cause of myelopathy especially in patients with marked kyphosis, when the cord was stretched over a prominent spondylotic bar.

Surgical treatment of CSM associated with dystonia is hazardous because it is difficult to immobilise the cervical spine post-operatively. Despite this, early recognition and treatment is necessary if an optimal result is to be achieved. Collar immobilisation is $\underset{\mathbb{D}}{Z}$ impractical in patients with dystonia or torticollis. In a small series of cases with CSM complicating athetoid- of dystonic cerebral palsy, Hirose and Kadoya found the most severe radiological changes at $\mathrm{C} 3 / 4$, and reported 0 good results with anterior discectomy, osteophytectomy and interbody fusion. ${ }^{9}$ Laminectomy may increase cord mobility by destabilising the cervical spine, so that the results from this approach may not. be as favourable, ${ }^{10}$ as demonstrated by the outcome in $\overrightarrow{\overline{\mathrm{N}}}$ our case 1 , and the lack of improvement following laminectomy in case 2.

Patients with dystonia or torticollis are at risk of $\frac{\bar{\sigma}}{\bar{\omega}}$ developing premature cervical spondylosis as a result $\vec{\nabla}$ of the excessive and continuous movement occurring $\stackrel{\circ}{\circ}$ in the joints of the cervical spine, ${ }^{9-12}$ and this complica- is tion is a potentially treatable cause of functional $\overrightarrow{0}$ deterioration.

\section{References}

1 Marsden CD. The problem of adult-onset idiopathic torsion dystonia and other isolated dyskinesias in adult life (including blepharospasm, oromandibular dys- $\vec{N}$ tonia, dystonic writer's cramp, and torticollis, or axiat $\vec{A}$ dystonia). Adv Neurology 1976;14:259-76.

2 Fahn S, Marsden CD, Calne DB. Classification ang investigation of dystonia. In: Marsden CD, Fahn eds. Movement Disorders 2. London: Butterworths 1987:332-58.

3 Nurick S. The pathogenesis of the spinal cord disordes associated with cervical spondylosis. Brain 1972;95 87-100.

4 Taylor AR, Aberd MB. Vascular factors in the myelopathy associated with cervical spondylosis. Neurology 1964;14:62-8.

5 Barnes MP, Saunders M. The effect of cervical mobility on the natural history of cervical spondylotic myelopathy. J Neurol Neurosurg Psychiatry 1984; 47:17-20.

6 Reid JD. The effects of flexion-extension movements of the head and spine upon the spinal cord and nerve roots. J Neurol Neurosurg Psychiatry 1960;23:214-21.

7 Waltz TA. Physical factors in the production of the myelopathy of cervical spondylosis. Brain 1967; 90:395-404.

8 Adams CBT, Logue V. Studies in cervical spondylotic myelopathy. Brain 1971;94:569-86.

9 Hirose G, Kadoya S. Cervical spondylotic radiculomyelopathy in patients with athetoid-dystonic cerebral palsy: clinical evaluation and surgical treatment. J Neurol Neurosurg Psychiatry 1984;47:775-80.

10 Kidron D, Steiner I, Melamed E. Late-onset progressive radiculomyelopathy in patients with cervical athetoiddystonic cerebral palsy. Eur Neurol 1987;27:164-6.

11 Angelini L, Broggi G, Nardocci N, Savoiardo M. Subacute cervical myelopathy in a child with cerebral palsy. Secondary to torsion dystonia? Child's Brain 1982;9:354-7.

12 Tunkel AR, Pasupuleti R, Acosta WR. Improvement of idiopathic torsion dystonia following dystonia-induced cervical subluxation. J Neurol Neurosurg Psychiatry 1986;49:957. 